\title{
Experience guides new CMA president on Health Accord
}

$\mathrm{D}$ r. Granger Avery's luxuriant mustache merges seamlessly into his mutton-chop whiskers, making him look less like a country doctor than a Victorian-era sergeant major.

"He's probably the only man left in the Western world who still wears mutton chops," jokes Dr. Derryck Smith, a long-time friend who, like Avery, is a past-president of the British Columbia Medical Association (BCMA, now Doctors of BC).

Avery, who's spent four decades in family practice in remote Port McNeill, BC, emits no parade-ground bellow.

"He's sort of politely relentless in improving care and seeking opportunities to see rural medicine improve," says Dr. Marshall Dahl, a clinical professor of medicine at the University of British Columbia (UBC), who also worked with Avery at the BCMA. "He'll never give up. He really does get results."

That tenacity and experience will serve him well in a challenging time as the 2016/17 President of the Canadian Medical Association (CMA).

His tenure begins as health care stakeholders finalize their positions in advance of talks with Ottawa and the provinces on a new national Health Accord. Avery, who worked on the previous accord, says he's buoyed by the Liberal government's attitude after the Conservatives refused to discuss health care.

The CMA wants the Canada Health Transfer increased to deal with the rising costs of an aging population particularly in some jurisdictions. They're also looking for federal funding for catastrophic pharmaceutical coverage and better access to continuing care, including home care and support for family caregivers.

Beyond the accord, Avery is looking for a broader vision of how Canadian health care should evolve since its decline in rankings among membernations of the Organisation for Economic Co-operation and Development.

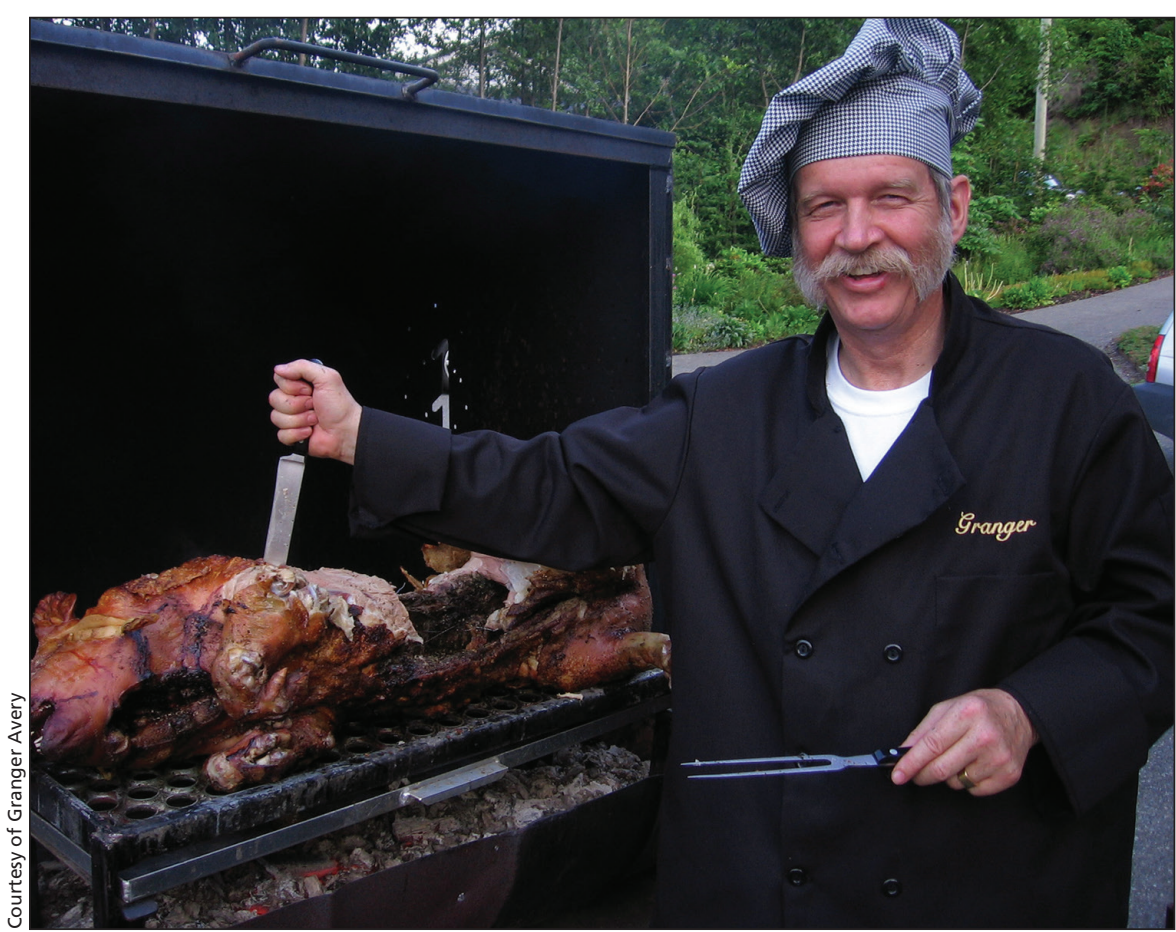

Dr. Granger Avery carves the beast during the annual pig roast for new medical students and residents in Port McNeill.

Restoring collegiality within the medical profession is a start. "I've seen how even the simple things like removing the coffee room in a hospital where people sit around and chat about this and that, even that has an effect on collegiality," he says.

"Our leadership needs to come as a group, as a profession, and it needs to lead toward the collaboration of all sectors of society to speak out to advance our application of health care."

Avery has always been a team player, says Dr. Jim Lane, who succeeded Avery as BCMA president in 1998. Avery's background in family practice brings a generalist's perspective to the system, and his ability to navigate the health system's complex relationships will also serve him well, Lane says. "He's been around. He certainly has the experience going back over at least two decades with medical politics."

In addition to negotiating a new accord, Avery, 69, also faces immediate issues, including the growing opioid crisis. He brings 20 years of clinical experience in addiction, as well as training physicians to recognize and treat it. People with addictions remain marginalized and the problem needs to be thought of differently, he says.

"It's symptomatic really of the fact our system doesn't address the fundamentals of why people are unwell," he says.

Avery will also have to contend with the ongoing controversy over the federal assisted-dying legislation. Critics complain it doesn't conform to the Supreme Court decision, including making it available to Canadians with terminal illnesses but not close to death, and those with early-stage dementia who want to give advance permission.

Avery has a wait-and-see attitude. The government's suggestion of a review after two years is "totally appropriate," he says. "It's up to Canadians and their political representatives to decide whether changes are needed." 


\section{Early aspirations}

Born in London, England, Avery was drawn to science at an early age, perhaps because his mother was a doctor. Medicine became a way to pursue that interest while helping people. He graduated from the University of London in 1971.

A love of travel took him to New Zealand, where he obtained a diploma in obstetrics and was senior house officer at the National Women's Hospital. En route home he stopped in BC to visit an aunt and uncle, and decided to do a residency in anesthesiology at Vancouver General Hospital.

There, he changed direction and looked for an opportunity in general practice. That led to Port McNeill, a forestry town on the northern tip of Vancouver Island accessible only by boat or logging road. It was a study in extremes: Vancouver General was one of Canada's largest hospitals with 1200 beds; Port McNeill had no hospital.
It was also a major transition for his new wife, Winnie, who was from Hong Kong and saw even Vancouver as a small town. The family thrived nonetheless. Today their daughter is an anesthetist in the United Kingdom and their sons are an architect and an airline executive.

For Avery, Port McNeill was no stagnant medical backwater. He developed expertise in rural medicine and the health issues of underserved local First Nations. He passed on his expertise by teaching at $\mathrm{UBC}$ and in professional groups. He also ventured into medical politics as president of the BCMA 1997/98 and twotime vice-chair of the CMA.

"Doctors really respect leaders who continue to be clinically active," says Dahl. "It keeps them grounded and sort of validated with what everybody's doing."

Outside medicine, Avery continues to indulge his passion for travel, often looking for the exotic, said Smith, who's vacationed with him. He recalls hunting for wild boars on foot, armed with spears in Spain.

Avery also operated a travel agency and continues to be the mostly handsoff president of WestCoast Helicopters, a charter and maintenance company with four bases and 18 helicopters. "One time he took me and my daughters for a ride and had the pilot take us through a loop in the middle of the air, which was something I didn't even know helicopters could do," says Smith.

Avery had stepped back from clinical practice to let younger colleagues do more of the work when he was tapped to run for CMA president.

"A few people approached me and said, look, our Canadian system isn't working as well as it should and [maybe] you could help with that," he said. "I'm grateful for the opportunity." - Steve Mertl, Vancouver, BC

CMAJ 2016. DOI:10.1503/cmaj.109-5312 